\title{
Caracterização física, química e bioquímica do mesocarpo interno de frutos do pequizeiro colhidos em diferentes estádios de desenvolvimento
}

\author{
Physical, chemical and biochemical characterization of pequi fruit \\ harvested at different stages of development
}

\author{
Brígida Monteiro Vilas Boas ${ }^{\mathrm{I}}$ Alessandra de Paiva Alves ${ }^{\mathrm{II}}$ Juliana Alvarenga Alves ${ }^{\mathrm{II}}$ \\ Luiz José Rodrigues III Tatielle Custódio AlvesII \\ Eduardo Valério de Barros Vilas Boas ${ }^{\mathrm{II}}$
}

RESUMO

O objetivo deste trabalho foi a caracterização física, química e bioquímica do pequi, produzido no sul de Minas Gerais, ao longo do seu desenvolvimento. Frutos coletados na $8^{a}, 9^{a}, 10^{a}$, $12^{\underline{a}}$ e $13^{\underline{a}}$ semanas após a antese foram selecionados quanto ao tamanho, cor da casca, ausência de injúrias e avaliados quanto à firmeza da polpa, teores de beta-caroteno, de açúcares solúveis totais e de pectinas total e solúvel, assim como quanto à atividade das enzimas pectinametilesterase (PME), poligalacturonase ( $P G)$, peroxidase (POD) e polifenoloxidase (PPO). Verificou-se que, com o avanço dos dias, após a antese nos frutos do pequizeiro, ocorre a síntese do beta-caroteno e de açúcares solúveis totais, redução da firmeza, solubilização das pectinas, ausência de PME, diminuição na atividade da PG e aumento nas atividades da POD e da PPO na polpa.

Palavras-chave: Caryocar brasiliense Camb., fruto do cerrado, amadurecimento, qualidade.

\section{ABSTRACT}

The aim of this study was to characterize physical, chemical and biochemical pequi fruit produced in southern Minas Gerais, Brazil, during their development stages. Fruits collected in the $8^{\text {th }}, 9^{\text {th }}, 10^{\text {th }}, 12^{\text {th }}$ and $13^{\text {th }}$ weeks after anthesis, were selected for size, skin color, and absence of injuries and evaluated according to firmness, levels of beta-carotene, total soluble sugars, and total and soluble pectins as well as the activity of pectinmethylesterase $(P M E)$, polygalacturonase $(P G)$, peroxidase $(P O D)$ and polyphenoloxidase (PPO). It was found that with the advancement of days after anthesis occurs in pequi fruits the synthesis of beta-carotene and total soluble sugars, reducing firmness, pectic solubilization, absence of PME activity, decrease in PG activity and increased in activities POD and PPO in the pulp.
Key words: Caryocar brasiliense Camb., cerrado fruit, ripening, quality.

\section{INTRODUÇÃO}

O pequi (Caryocar brasiliense Camb.) apresenta alto valor energético e nutricional, por ser uma fonte de lipídios, proteínas, vitaminas e sais minerais, o que o torna um fruto importante na alimentação das populações da região do Cerrado (RODRIGUES et al., 2009). Contudo, no sul de Minas Gerais, ele ainda é pouco explorado pela população local, devido à falta de conhecimento, restringindo seu uso à culinária, diferentemente do observado no norte de Minas Gerais, onde, apesar de esse fruto ser explorado de forma extrativista, é utilizado na alimentação e como fonte de renda.

RODRIGUES (2005) recomenda que a colheita do pequi seja realizada no $84^{\circ}$ dia (12 ${ }^{\underline{a}}$ semana) após a antese, que corresponde à maturidade fisiológica, no qual o fruto atingiu o máximo acúmulo de massa e de diâmetros longitudinal e transversal, bem como síntese de vários compostos no mesocarpo interno (polpa comestível), entre eles o ß-caroteno e a vitamina C, representando o estádio correspondente à sua maturidade.

O amaciamento de frutos durante o seu amadurecimento implica modificações de polissacarídeos de parede celular (PC) (CHITARRA

\footnotetext{
Instituto Federal de Educação, Ciência e Tecnologia do Sul de Minas Gerais, Machado, Campus Machado, Rod. Machado, Paraguaçu, Km 3, Santo Antônio, 37750-000, Machado, MG, Brasil. E-mail: brigida@mch.ifsuldeminas.edu.br. Autor para correspondência.

IIDepartamento de Ciência dos Alimentos, Universidade Federal de Lavras (UFLA), Lavras, RS, Brasil.

IIIDepartamento de Alimentos e Nutrição (DAN), Faculdade de Nutrição (FANUT), Universidade Federal de Mato Grosso (UFMT), Cuiabá, MT, Brasil.
} 
\& CHITARRA, 2005). Os reflexos econômicos desse amaciamento têm estimulado o desenvolvimento de uma série de pesquisas envolvendo o estudo das bases bioquímicas do metabolismo da PC durante o desenvolvimento e maturação de frutos. A diminuição na firmeza (textura da polpa) durante o amadurecimento tem sido atribuída a modificações e à degradação dos componentes da parede celular, tais como celulose, hemiceluloses e pectinas (CHITARRA \& CHITARRA, 2005). A degradação de pectina geralmente é acompanhada por aumento na atividade de hidrolases da PC, tais como poligalacturonase (PG) e pectinametilesterase (PME) (OLIVEIRA et al., 2006).

A caracterização do pequi durante os estádios de desenvolvimento permite o conhecimento das principais mudanças que levam ao amadurecimento do fruto, o que é fundamental na pós-colheita. Em vista disso, este trabalho teve como objetivo a caracterização física, química e bioquímica dos frutos do pequizeiro, produzidos no sul de Minas Gerais, e colhidos em diferentes estádios de maturação.

\section{MATERIAL E MÉTODOS}

Os pequis foram coletados em área com formação típica do Cerrado, localizada a $12 \mathrm{~km}$ do município de Itumirim, sul do Estado de Minas Gerais, Brasil. A altitude do local é de $871 \mathrm{~m}$, situando-se entre as coordenadas geográficas $21^{\circ} 19^{\prime} 01^{\prime \prime}$ de latitude Sul e 44 52 '16" de longitude Oeste, com clima subquente e subúmido (ANUÁRIO 1999).

Os frutos foram coletados, ao acaso, em cinco estádios de desenvolvimento (8, 9, 10, 12 e 13 semanas após a antese), de acordo com o indicado por RODRIGUES (2005), sendo selecionados quanto à presença de defeitos ou pragas. Eles foram lavados com detergente neutro e água corrente para a retirada das sujidades superficiais provenientes do campo e sanificados em solução de hipoclorito de sódio $300 \mathrm{mg} \mathrm{L}^{-1}$, por 15 minutos. Em seguida, amostras do mesocarpo interno dos frutos foram separadas e avaliadas quanto:

Beta-caroteno (mg $100 \mathrm{~g}^{-1}$ de polpa) extraído com acetona:hexano (4:6) e determinado por espectrometria, de acordo com NAGATA \& YAMASHITA (1992). O teor de beta-caroteno foi expresso em miligrama por $100 \mathrm{~g}$, após o seu equacionamento: Beta-caroteno $=0,216 \mathrm{~A}_{663}$ $1,22 A_{645}-0,304 A_{505}+0,452 A_{453}$, sendo: $A_{663}, A_{645}$, $\mathrm{A}_{505}$ e $\mathrm{A}_{453}$ leituras de absorbância nos respectivos comprimentos de onda.
Açúcares solúveis totais (g de glicose por $100 \mathrm{~g}^{-1}$ de polpa) - determinados espectrofotometricamente em extrato alcoolico, usando-se o método de Antrona (DISCHE, 1962).

Firmeza (N) - foi determinada na região equatorial de três pirênios, em dois pontos opostos, correspondendo a uma média de 6 leituras para cada repetição. Os pirênios foram dispostos em plataforma HDP/90, com o auxílio de um texturômetro Stable Micro System, modelo TAXT2i; utilizando a sonda tipo agulha $\mathrm{P} / 2 \mathrm{~N}$ (2mm de diâmetro), que mediu a força de penetração desta nos frutos, numa velocidade de $10 \mathrm{~mm} \mathrm{~s}^{-1}$ e uma distância de penetração de $3 \mathrm{~mm}$.

Pectinas total e solúvel (mg de ácido galacturônico $100 \mathrm{~g}^{-1}$ de polpa) - extraídas segundo a técnica padronizada por McCREADY \& McCOMB (1952) e determinadas colorimetricamente conforme técnica descrita por BITTER \& MUIR (1962).

Atividade de pectinametilesterase (PME) e de poligalacturonase (PG) - os extratos brutos das enzimas foram obtidos segundo metodologia descrita por BUESCHER \& FURMANSKI (1978) e modificada por VILAS BOAS (1995). A atividade da PME foi quantificada usando-se o método proposto por HULTIN et al. (1966) e RATNER et al. (1969), com modificações de VILAS BOAS (1995). Uma unidade de PME foi definida como a quantidade de enzima capaz de catalisar a desmetilação de pectina correspondente ao consumo de $1 \mathrm{nmol}$ de $\mathrm{NaOH}$ por minuto. A atividade da PG foi determinada de acordo com MARKOVIC et al. (1975), com modificações de VILAS BOAS (1995), sendo expressa em nmol de ácido galacturônico por grama de polpa por minuto.

Atividade de peroxidase (POD) - foi determinada de acordo com a metodologia descrita por FLURKEY \& JEN (1978), sendo expressa em unidades de atividade enzimática (UAE) por minuto por grama. A atividade foi definida como aumento de 0,1 unidade de absorbância a 470nm por minuto.

Atividade de polifenoloxidase (PPO) extração realizada de acordo com o método proposto por MATSUNO \& URITANE (1972) e a atividade expressa em unidade de atividade enzimática (capacidade de alterar 0,001 de absorbância) por minuto por grama de tecido fresco (UAE $\mathrm{min}^{-1} \mathrm{~g}^{-1}$ ), segundo o método de TEISSON (1979).

$\mathrm{O}$ experimento foi conduzido em delineamento inteiramente casualizado (DIC), disposto por uma fatorial simples, sendo constituído por cinco estádios de desenvolvimento (8, 9, 10, 12 e 13 semanas após a antese), com quatro repetições, constituídas de 15 pirênios. Os dados obtidos foram submetidos à análise de variância (ANOVA) 
utilizando o teste de média Tukey ou regressão em função do tempo. Utilizou-se o programa estatístico SISVAR versão 5.0 (FERREIRA, 2000).

\section{RESULTADOS E DISCUSSÃO}

Os estádios de desenvolvimento afetaram significativamente as variáveis beta-caroteno, açúcares solúveis totais, firmeza, pectina solúvel, poligalacturonase, peroxidase e polifenoloxidase, mas não influenciaram a pectina total. Os teores de beta-caroteno do mesocarpo interno do pequi aumentaram linearmente durante o desenvolvimento (Figura $1 \mathrm{~A}$ ), indicando síntese desse pigmento. Segundo AZEVEDO MELEIRO \& RODRIGUEZ AMAYA (2004), os principais carotenoides presentes na polpa do pequi são a violaxantina, luteína e a zeaxantina, com pequenas quantidades de betacriptoxantina, beta-caroteno e neoxantina.

Observou-se acréscimo nos teores de açúcares solúveis totais do mesocarpo interno do pequi até a décima semana, com posterior estabilidade até o final do desenvolvimento (Figura 1 B). Segundo CHITARRA \& CHITARRA (2005), com a evolução da maturação, há aumento da concentração de açúcares simples até o completo amadurecimento, com declínio posterior em função de sua utilização como fonte de energia.
RODRIGUES (2005) verificou, em estudo sobre a caracterização física e química do pequi cultivado no sul de Minas Gerais, aumento linear nos teores de sólidos solúveis, de 2,83\% para 5,90\%, entre a $4^{\text {a }}$ e a $12^{\text {a }}$ semana após a antese. O comportamento crescente dos teores de açúcares observado neste trabalho pode ser devido à contribuição dos sólidos solúveis conforme relatado pelo autor supracitado.

Com o avanço dos dias, após a antese, houve um decréscimo nos valores de firmeza (Figura $1 \mathrm{C}$ ). O amaciamento dos tecidos está associado com mudanças no grau de polimerização e composição de açúcares simples que compõem os polissacarídeos, resultando em alterações na estrutura da parede celular, com diminuição na coesão das células e perda de firmeza dos tecidos (CHITARRA \& CHITARRA, 2005).

O estádio de desenvolvimento não influenciou significativamente os teores de pectina total do mesocarpo interno do pequi, que foi, em média, 3338,96 $( \pm 180,55) m g$ de ácido galacturônico $100 \mathrm{~g}^{-1}$.

Os teores de pectina solúvel aumentaram até a nona semana, em seguida mantiveram-se estáveis até a décima segunda semana, culminando com incremento acentuado na décima terceira semana (Figura 1 D), indicando que ocorreu intensificação na solubilização da pectina. É importante ressaltar que o aumento nos teores de pectina solúvel no mesocarpo

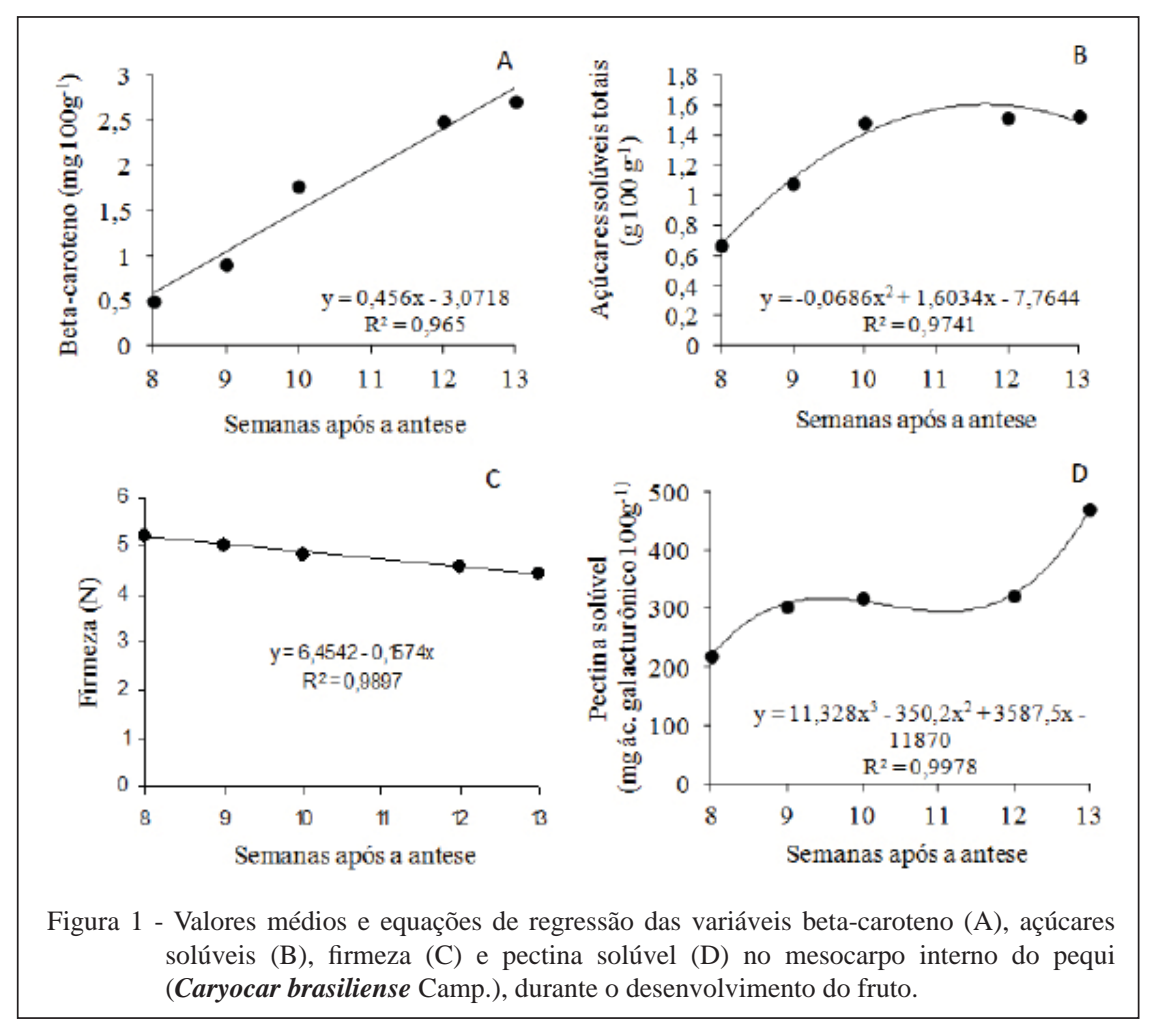

Ciência Rural, v.43, n.12, dez, 2013. 
interno de pequi coincidiu com a redução dos valores de firmeza (Figura $1 \mathrm{C}$ ). O processo de solubilização das pectinas contribui para o amaciamento dos tecidos em decorrência da redução da força de coesão entre as células. Como as pectinas contribuem para a resistência mecânica da parede celular e para a adesão entre células, qualquer modificação nas suas características resulta em alterações na textura dos frutos (CHITARRA \& CHITARRA, 2005).

A atividade da pectinametilesterase (PME) não foi detectada no mesocarpo interno do pequi colhido nos cinco estádios de desenvolvimento estudados. Resultados semelhantes foram relatados por OLIVEIRA et al. (2006) na polpa de frutos de pequi coletados em três épocas diferentes (na árvore, antes da queda natural; no chão, após a queda natural; e no chão após a queda natural, seguido de armazenamento ao ambiente por três dias). De acordo com esses autores, a ausência de atividade dessa enzima na polpa do pequi tem pouco ou nenhuma contribuição nas alterações na textura que ocorrem durante o amadurecimento do fruto. Eles acrescentaram que esse comportamento pode ser devido ao baixo grau de metoxilação das pectinas que constituem a parede celular do pequi.

A atividade da poligalacturonase (PG) foi influenciada significativamente pelo estádio de desenvolvimento e apresentou baixa atividade no mesocarpo interno do pequi, quando comparado ao resultado encontrado por OLIVEIRA et al. (2006). A atividade dessa enzima diminuiu linearmente com o avanço dos dias após a antese (Figura 2 A) e, ao mesmo tempo, apresentou comportamento inverso ao da variável pectina solúvel, sugerindo que a solubilização das substâncias pécticas (Figura 1 D) não está diretamente relacionada à ação da PG e que outras enzimas estão envolvidas no amaciamento da polpa do pequi (OLIVEIRA et al., 2006). Por outro lado, cabe ressaltar que, mesmo níveis muito baixos de PG são suficientes para catalisar a hidrólise das pectinas, uma vez que, segundo HADFIELD \& BENNETT (1998), reduções de 80\% na atividade da PG em frutos de tomate apresentaram pouco efeito sobre a redução na hidrólise de pectinas, indicando que, em algumas espécies, a PG pode estar presente em excesso.

OLIVEIRA et al. (2006) detectaram baixa atividade da PG (45-64nmol $\left.\mathrm{min}^{-1} \mathrm{~g}^{-1}\right)$ na polpa de frutos do pequizeiro coletada em três épocas (na árvore, antes da queda natural; no chão, após a queda natural; e no chão após a queda natural, seguido de armazenamento ao ambiente por três dias) e submetidos a dois tipos de congelamento da polpa (em nitrogênio líquido e em freezer), cujos valores são superiores aos observados neste trabalho.

As variáveis polifenoloxidase (PPO) e peroxidase (POD) foram significativamente afetadas pelo estádio de desenvolvimento, cujo

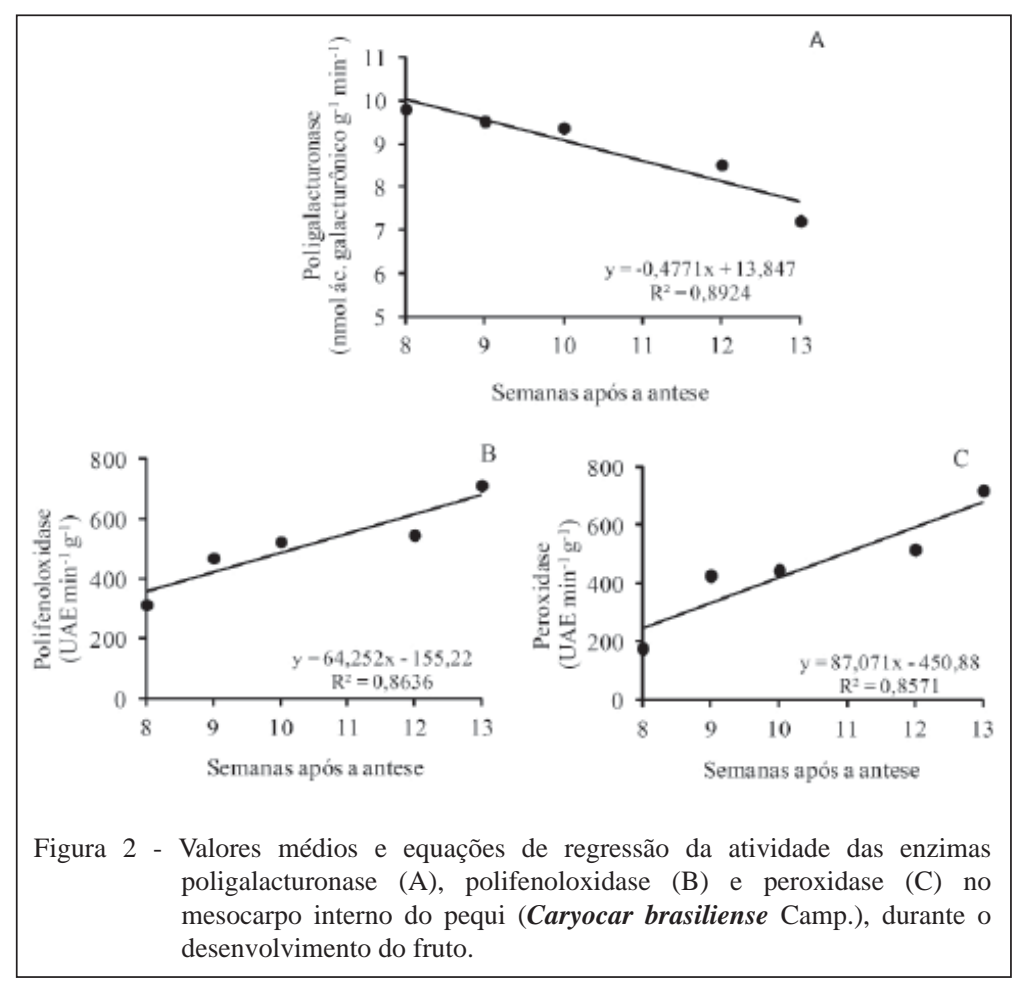

Ciência Rural, v.43, n.12, dez, 2013. 
comportamento foi caracterizado por aumento linear na atividade enzimática com o avanço dos dias após a antese (Figuras 2 B, 2 C). Comportamento inverso foi verificado por GONÇALVES et al. (2006) em figos colhidos em diferentes estádios de desenvolvimento, que relataram maior atividade dessas enzimas nos frutos verdes.

$\mathrm{O}$ aumento da atividade da peroxidase está associado, entre outros, com a biossíntese de compostos das paredes celulares em resposta a danos mecânicos nos tecidos, resistência a doenças e mecanismos de cura ou reparo de ferimentos nos tecidos e escurecimento (CHITARRA \& CHITARRA, 2005).

\section{CONCLUSÃO}

De acordo com os parâmetros físicos, químicos e bioquímicos avaliados, com o avanço dos dias após a antese nos frutos do pequizeiro, ocorrem a síntese do beta-caroteno e de açúcares solúveis totais, redução da firmeza, solubilização das pectinas, diminuição na atividade da PG e aumento nas atividades da peroxidase e da polifenoloxidase na polpa.

\section{AGRADECIMENTOS}

Os autores agradecem à Fundação de Amparo à Pesquisa do estado de Minas Gerais (FAPEMIG), pela concessão da bolsa de pós-doutorado a primeira autora; ao Conselho Nacional de Desenvolvimento Científico e Tecnológico (CNPq) e à Coordenação de Aperfeiçoamento de Pessoal de Nível Superior (CAPES), pelo apoio financeiro ao projeto.

\section{REFERÊNCIAS}

ANUÁRIO ESTATÍSTICO DO BRASIL, 1999. Rio de Janeiro: IBGE, 1999. V.57, 1096p.

AZEVEDO-MELEIRO, C.H.; RODRIGUEZ-AMAYA, D.B. Confirmation of the identity of the carotenoids of tropical fruits by HPLC-DAD and HPLC-MS. Journal of Food Composition and Analysis, San Diego, v.17, p.385-396, 2004. Disponível em: <http:// www.sciencedirect.com/science/article/pii/S0889157504000298>. Accesso em: 20 nov. 2011. doi:10.1016/j.jfca.2004.02.004.

BITTER, T.; MUIR, H.M. A modified uronic acid carbazole reaction. Analytical Biochemistry, New York, v.4, n.4, p.330334, 1962. Disponível em: <http://www.sciencedirect.com/ science/article/pii/0003269762900957>. Accesso em: 5 nov. 2011. doi:10.1016/0003-2697(62)90095-7.

BUESCHER, R.W.; FURMANSKI, R.J. Role of pectinesterase and polygalacturonase in the formation of woolliness in peaches. Journal of Food Science, Chicago, v.43, n.1, p.264266, 1978. Disponível em: <http://onlinelibrary.wiley.com/ doi/10.1111/j.1365-2621.1978.tb09788.x/abstract>. Accesso em: 20 nov. 2011. doi:10.1111/j.1365-2621.1978.tb09788.x.
CHITARRA, M.I.F.; CHITARRA, A.B. Pós-colheita de frutas e hortaliças: fisiologia e manuseio. 2.ed. rev. e ampl. Lavras: UFLA, 2005. 785p.

DISCHE, E. Color ractions of carbohydrates. In: WHISTLER, R.L.; WOLFRAN, M.L. Methods in carbohydrates chemistry. New York: Academic, 1962. V.1, p.477-512.

FERREIRA, D.F. Análises estatísticas por meio do SISVAR para windows versão 4. 0. In: REUNIÃO ANUAL DA REGIÃO BRASILEIRA DA SOCIEDADE INTERNACIONAL DE BIOMETRIA, 45., 2000, São Carlos, SP. Programa e Resumo... São Carlos: UFSCar, 2000. p.235.

FLURKEY, W.H.; JEN, J.J. Peroxidase and polyphenol oxidase activities in developing peaches. Journal of Food Science, Chicago, v.43, n.6, p.1826-1828, 1978. Disponível em: <http://onlinelibrary. wiley.com/doi/10.1111/j.1365-2621.1978.tb07424.x/abstract> . Accesso em: 20 nov. 2011. doi:10.1111/j.1365-2621.1978.tb07424.x.

GONÇALVES, C.A.A. et al. Caracterização física, físicoquímica, enzimática e de parede celular em diferentes estádios de desenvolvimento da fruta de figueira. Ciência e Tecnologia de Alimentos, Campinas, v.26, n.1, p.220-229, 2006. Disponível em: <http://www.scielo.br/scielo.php?script=sci_art text\&pid=S0101-20612006000100035>. Acesso em: jan. 2012. doi:10.1590/S0101-20612006000100035.

HADFIELD, K.A.; BENNETT, A.B. Polygalacturonases: many genes in search of a function. Plant Physiology, Washington, v.117, p.337-343, 1998. Disponível em: <http://www.plantphysiol. org/content/117/2/337.full.pdf+html>. Acesso em: jan. 2012. doi: 10.1104/pp.117.2.337.

HULTIN, H.O. et al. Pectin methyl esterases of the banana. Purification and properties. Journal of Food Science, Chicago, v.31, n.3, p.320-327, 1966. Disponível em: <http://onlinelibrary. wiley.com/doi/10.1111/j.1365-2621.1966.tb00500.x/abstract>. Acesso em: jan. 2012. doi:10.1111/j.1365-2621.1966.tb00500.x.

MARKOVIC, O. et al. Pectolytic enzymes from banana. Collection Czechoslovak Chemistry Community, Pregue, v.40, n.3, p.769-774, 1975. Disponível em: <http://onlinelibrary.wiley. com/doi/10.1111/j.1365-2621.1966.tb00500.x/abstract>. Acesso em: jan. 2011. doi:10.1135/cccc19750769.

MATSUNO, H.; URITANE, I. Phisiological behavior of peroxidase emzymes in sweet potate root tissue injured by cutting or black root. Plant and Cell Physiology, Tokyo, v.13, n.6, p.1091-1101, 1972. Disponível em: <http://pcp.oxfordjournals. org/content/13/6/1091.short>. Acesso em: jan. 2011.

McCREADY, R.M.; McCOMB, E.A. Extraction and determination of total pectic materials in fruit. Analytical Chemistry, Washington, v.24, n.12, p.1586-1588, 1952. Disponível em: $<$ http://pubs.acs.org/doi/abs/10.1021/ac60072a033>. Accesso em: nov. 2011. doi: 10.1021/ac60072a033.

NAGATA, M.; YAMASHITA, I. Simple method for simultaneous determination of chlorophyll and carotenoids in tomato fruit. Nippon Shokuhin Kogyo Gakkaishi, Tokyo, v.39, n.10, p.925928, 1992. Disponível em: <http://cse.naro.affrc.go.jp/mnagata/ pigment2.pdf>. Accesso em: 20 nov. 2011.

OLIVEIRA, M.N.S. et al. Estádio de maturação dos frutos e fatores relacionados aos aspectos nutritivos e de textura da polpa 
de pequi (Caryocar brasiliense Camb.). Revista Brasileira de Fruticultura, Jaboticabal, v.28, n.3, p.380-386, 2006. Disponível em: <http://www.scielo.br/scielo.php?pid=S010029452006000300010\&script=sci_arttext $>$. Accesso em: 20 nov. 2011. doi: 10.1590/S0100-29452006000300010.

RATNER, A. et al. Activity of pectin esterase and cellulase in the abcission zone of citrus leaf explants. Plant Physiology, Washington, v.44, n.12, p.1717-1723, 1969. Disponível em: <http://www.ncbi.nlm.nih.gov/pmc/articles/PMC396333/>. Accesso em: 20 nov. 2011. doi:10.1104/pp.44.12.1717.

RODRIGUES, L.J. et al. Caracterização do desenvolvimento de pequi (Caryocar brasiliense) temporão do sul de Minas Gerais. Pesquisa Agropecuária Tropical, Goiânia, v.39, n.3, p.260-265, 2009. Disponível em: <http://www.revistas.ufg.br/index.php/pat/ article/view/4024/5372,> Acesso em: jan. 2013. doi:<http://www. doaj.org/doaj?func $=$ openurl\&genre $=$ article\&issn $=19834063 \&$ date $=2009 \&$ volume $=39 \&$ issue $=3 \&$ spage $=260>$.

RODRIGUES, L.J. O Pequi (Caryocar brasiliense Camb.): ciclo vital e agregação de valor pelo processamento mínimo. 2005. 125f. (Mestrado em Ciência dos Alimentos) - Universidade Federal de Lavras, Lavras, MG.

TEISSON, C. Le brunissement interne de l'ananas. I-Historique. II-Materiel et méthodes. Fruits, Paris, v.34, n.4, p.245-281, 1979.

VILAS BOAS, E.V.B. Modificações pós-colheita de banana 'Prata' (Musa acuminata $x$ Musa balbisiana grupo AAB) g-irradiada. 1995. 73f. Dissertação (Mestrado em Ciência dos Alimentos) - Universidade Federal de Lavras, Lavras, MG. 